\title{
The European project MYRRH: Use of mycorrhizal fungi for the phytostabilisation of radio-contaminated environments
}

\author{
S. Declerck, C. Leyval', I. Jakobsen ${ }^{2}, Y$. Thiry', C. Heine ${ }^{4}$ and B. Delvaux ${ }^{4}$ \\ Université Catholique de Louvain, Mycothèque de I'Université Catholique de Louvain (MUCL), \\ Unite de Microbiologie, 3 place Croix du Sud, 1348 Louvain-la-Neuve, Belgium \\ ${ }^{1}$ Centre National de la Recherche Scientifique, Centre de Pédologio Biologique, \\ 17 rue Notre-Dame des Pauvres, BP. 5, 54501 Vandœuvre-les-Nancy, France \\ ${ }^{2}$ Riso National Laboratory, Plant Biology and Biogeochemistry Department, \\ 399 Frederiksborgvej, 4000 Roskilde, Denmark \\ ${ }^{3}$ CEN-SCK, Radiation Protection Research Department, 200 Boeretang, 2400 Mol, Belgium \\ ${ }^{4}$ Université Catholique de Louvain, Unité des Sciences du Sol, 2/10 place Croix du Sud, \\ 1348 Louvain-la-Neuve, Belgium
}

\begin{abstract}
Micro-orgarisms have a significant influence on the fate of radionuclides (RN) in terrestrial ecosystems, with a wealth of physico-chemical and biological mechanisms impacting mobility and speciation [1]. Among these soil micro-organisnus, mycorrhizal fungi are active components of the thizosphere. They inhabit roots and develop in the surrounding environment, therefore they are located at the interface between roots and soil. Since the Chernobyl accident an increased attention was given to these symbiotic organisms which were assumed to influence RN acquisition and hence RN bio-cycling. However, the precise role of AMF in RN mobilization and transfer and the mechanisms involved are still a matter of speculation. Most results were obtained with radiocesium. The present contribution intends to summarize what we know on the roles of these symbiotic fungi on radiocesium uptake/accumulation and on the potential mechanisms involved, by reference to selected studies.
\end{abstract}

\section{INTRODUCTION}

Management of cultivated and semi-natural ecosystems which have been exposed to diffuse radionuclide $(\mathrm{RN})$ pollution (e.g. radiocesium) as well as remediation of former industrial sites contaminated with both RN's and heavy metals are of major concern in several European countries. Adapted strategies must be developed to optimise the socio-economical value of such sites and to avoid radiation exposure due to uncontrolled RN dispersion or leaching, which can burden food chain and/or water reservoir.

Because plants function as a principal entry point of RN's into the food chain, it is important to analyse the distribution of RN's in plants, the mechanisms sustaining uptake, accumulation and redistribution (see [2] for review) and the processes involving mineral surfaces and roots in the rhizosphere [3]. Until the last decade, most research has been conducted with too little attention paid to the microbial inhabitants of soil. However, in situ, plants are intimately associated with microorganisms, which could have a substantial effect on RN. They can directly act on several processes affecting RN fate: solubilization, complexation, sequestration, immobilization, transformation, precipitation [1]. Of these organisms, the mycorrhizal fungi represent a key active component that develops bridges connecting roots with soil particles. Consequently, these organisms considerably increase the root zone exploration for the uptake of nutrients and trace elements, and influence the microbial population developing within this zone. Strictly speaking the majority of plants do not have a thizosphere but a mycorrhizosphere. In heavy-metal contaminated soils, mycorrhizal fungi have been shown to decrease metal toxicity to plants, reducing translocation from root to shoot (see $[4,5]$ for review). These root symbionts could also influence RN acquisition by plants and hence RN biocycling. Their role in this process is, however, practically unknown.

Within the framework of the "Nuclear Energy" programme of the European Commission, the "MYRRH" project was recently funded to decipher and understand the role of mycorrhizal fungi in the mobilization and transfer of RN's, more precisely $\mathrm{Cs}$ and $\mathrm{U}$, to plants. The present contribution intends to summarize what we know on these roles for $\mathrm{Cs}$ and on the potential mechanisms involved by reference to selected studies. 


\section{RADIONUCLIDE UPTAKE AND ACCUMULATION BY MYCORRHIZAL FUNGI}

In 1977 and 1978 [6, 7] a survey of fungi in five European countries revealed accumulation of radiocesium in the basidiocarps of various ectomycorthizal (ECM) fungi i.e. Cortinarius armillatus, Paxillus involutus, Iaciarius rufus, Suillus grevillei, Amanita rubescens. The same survey conducted after the Chemobyl accident [8] revealed a similar pattern of Cs accumulation with Cs contents 3 to 5 fold larger in 1986 than in 1977-1978. Cs accumulation appeared to be species-specific in both surveys. For example, $P$ filamentosus did not accumulate Cs, whereas $P$. involutus did [8]. These observations were confirmed in surveys conducted in Japanese forests $[9,10]$. Up to 100 mushroom species (ECM and saprophytic) were analysed. The results revealed a high variability between species $(<4-16000 \mathrm{~Bq} / \mathrm{kg}$ dry weight, see [9]) and a mean value markedly higher in basidiocarps than in plants collected at the same sites. This clearly demonstrated the ability of mushrooms to accumulate $\mathrm{Cs}$ in their basidiocarps. The highest concentrations were obtained in ECM (see [9]) i.e. Hebeloma sp., Tricholoma flavovirens, L. corrugis, Sarcodon aspratus, Rhodophyllus crassipes, $R$ rhodopolus, $C$. saturninus demonstrating that symbiotic mushrooms may accumulate more $C$ s than saprophytes. In addition to these observations, it appears that the habitat of the mycelia i.e. fallen tree, litter layer, surface soil layer $(0-5 \mathrm{~cm})$ and deeper soil layer $(>5$ $\mathrm{cm}$ ) would also reflect the Cs concentration in many mushrooms [9]. The fungi developing in the surface soil layer $(0-5 \mathrm{~cm})$ accumulate more ${ }^{137} \mathrm{Cs}$ than the other ones.

While considerable data have been collected under natural and semi-natural ecosystems on ${ }^{137} \mathrm{Cs}$ accumulation by ECM and saprophytic fungi, no explicit information is available on the RN accumulation in AMF species, although these root symbionts are present in nearly $80 \%$ of vascular land plants.

\section{EFFECTS OF MYCORRHIZAL FUNGI ON TRANSFER OF RADIONUCLIDES TO PLANT}

Despite the fact that mycorrhizal fungi markedly affect mineral nutrition of plants, little research has been conducted on the effects of ECM and AMF on the uptake of Cs by plants. Few mycorrhizal species and plants have been investigated and most results are inconsistent. Some AMF were shown to enhance Cs uptake, whereas other appeared to decrease Cs plant content. An increase of Cs was reported in leaf tissues of Paspalum notatum colonised by two out of ten AMF species [12], in AMF Melilotus officinalis [13] and in Festuca ovina [14], whereas no marked uptake was observed in AMF Sorghum sudanense as compared to the control plants [13]. A significant decrease in Cs uptake was reported for AMF Trifolizm repens [14] and Agrost is tenuis [11] as compared to non-mycomhizal controls.

In contrast to the few data accumulated with AMF species and herbaceous plants, no literature, to our knowledge, rigorously reports the impact of ECM in Cs uptake and transfer to plants. However, it appears that $\mathrm{Cs}$ concentration is generally higher in the basidiocarps $[9,10]$ than in the plants, suggesting the absence/reduced transfer of Cs to plants via the mycelium.

\section{MECHANISMS INVOLVED IN ACCUMULATION/TRANSFER OF RADIONUCLIDES IN MYCORRHIZAL FUNGI}

Basic knowledge of all potential mechanisms involved in uptake of Cs and RN in general is a prerequisite for the design of countermeasures to reduce transfer of radioelements to plants. Multiple mechanisms of RN uptake by plants roots have been explored [2] as well as the processes involving mineral surfaces in the rhizosphere [3]. However, the mycorrhizal effects on RN plant uptake remains a black box and few or no soil and plant-based countermeasures were evaluated for effects upon AMF-mediated plant uptake of RN [11]. Strictly speaking, the vast majority of plants do not have roots but mycorrhizas, therefore playing a vital role in uptake and mobilisation of minerals, toxic elements and $R N$.

Mechanisms for mycorrhizal Cs uptake have never been explored so far. Although, it appears from a recent study that $\mathrm{AMF}$ could possibly sequester $\mathrm{Cs}$ in the extraradical mycelium i.e. outside the roots [11]. This hypothesis was based on the observation of a drastic decrease of Cs content of $A$. tenuis plants 
colonised by Glomus mosseae as compared to the non-mycorrhizal controls. Accumulation/sequestration in fungal structures has been demonstrated earlier $[8,14]$ and hypothesised for toxic elements such as aluminium [15]. Fixation on extramatrical binding sites, sequestration within extraradical mycelium or intraradical structures i.e. vesicles, precipitation, ... are potential mechanisms that should be explored. The development in recent years of in vitro cultivation systems of AMF on transgenic host roots [16] may represent a powerful model system to unravel these mechanisms. Such system was recently applied to study the transfer of ${ }^{32} \mathrm{P}$ from a compartment in which only mycelium was allowed to develop, into a physically separated second compartment containing the mycorrhizal root [17]. Within the MYRRH project, such system is applied to clarify the effects of AMF on Cs and U uptake and mobilisation as well as on the mechanisms involved.

\section{CONCLUSION}

Most of available literature data indicate that ECM accumulates Cs into carpophores in a matter that varies from species to species. Therefore their role as bioindicators of Cs pollution could be taken into consideration. The role of AMF on the fate of $\mathrm{Cs}$ is more controversial. Some authors observed an increase in uptake and transfer to plants, while others suggested a sequestration into the extraradical structures of the fungus, therefore reducing transfer to plants. At present, it appears difficult to draw firm conchusions on the precise role of AMF with regard to uptake and transfer/accumulation of Cs and the underlying mechanisms are still to be resolved. The in vitro culture system represent the most promising avenue to enter this black box and is considered in the European project MYRRH "Use of mycortizal fungi for the phytostabilisation of radio-contaminated environments". This project based on a consortium of five European laboratories intends to clarify the role of mycorrhizal fungi in $\mathrm{Cs}$ and $U$ uptake/mobilisation and to identify the mechanisms involved.

\section{Acknowledgments}

This work was supported by EU contract FIGE-CT-2000-00014 "Use of mycorrhizal fungi for the phytostabilisation of radio-contaminated environments".

\section{References}

[1] Gadd G.M., Endeavour 20 (1996) 150-156.

[2] White P.J. and Broadley M.R. New Phytol. 147 (2000) 241-256

[3] Delvaux B., Kruyts N. and Cremers A. Environ. Sci. Technol. 34 (2000) 1489-1493.

[4] Gałli U., Schüepp H. and Brunold C., Physiol. Plant. 92 (1994) 364-368.

[5] Leyval C., Turneau K., and Haselwandter K., Mycorrhiza 7 (1997) 139-153.

[6] Hasel wandter K., Zeitschrift für Pilzkunde 43 (1977) 323-326.

[7] Haselwandter K. Heallh Phys. 34 (1978) 713-715.

[8] Haselwandter K. and Berreck M., Trans. Br. Mycol. Soc. 90 (1988) 171-174.

[9] Yoshida S. and Muramatsu Y. Sci. Tot. Environ. 157 (1994) 197-205

[10] Tsukada H., Shibata H. and Sugiyama H., J. Environ. Radioactiv. 39 (1998) 149-160.

[11] Berreck M. and Haselwandter K., Mycorrhiza 10 (2001) 275-280.

[12] McGraw A.C., Gamble J.F. and Schenck N.C., Phytopathology 69 (1979) 1038-1041.

[13] Rogers R.D. and Williams S.E., Soil Biol. Biochem. 18 (1986) 371-376.

[14] Dighton J. and Terry G.M., in Fungi and environmental change, edited by J.C. Frankland, N. Magan and G.M. Gadd. (Cambridge University Press, Cambridge, 1996).

[15] Rufyikiri G., Declerck S., Dufey J.E. and Delvaux B., New Phytol. 148 (2000) 343-352.

[16] Declerck S., Strullu D.G. and Plenchette C., Mycologia. 90 (1998) 579.585.

[17] Joner E.J., Ravnskov S. and Jakobsen I., Biotechnol. Lett., 22 (2000) 1705-1708. 